\title{
Photocatalytic Degradation of Polynitrophenols on Various Commercial Suspended or Deposited Titania Catalysts Using Artificial and Solar Light
}

\author{
Hinda Lachheb, ${ }^{1}$ Ammar Houas, ${ }^{1}$ and Jean-Marie Herrmann ${ }^{2}$ \\ ${ }^{1}$ Equipe de Catalyse et Environnement, URECAP (99/UR/11-20) Ecole Nationale d’Ingénieurs de Gabès, \\ Faculté des Sciences de Gabès, Campus Universitaire, 6072 Gabès, Tunisia \\ ${ }^{2}$ Institut de Recherches sur la Catalyse et l'Environnement de Lyon (IRCELYON), (UMR CNRS5256), Université de Lyon, \\ 2 Avenue Albert Einstein, F-69626 Villeurbanne Cedex, France \\ Correspondence should be addressed to Hinda Lachheb, lachheb2001@yahoo.fr
}

Received 26 June 2007; Revised 10 October 2007; Accepted 27 January 2008

Recommended by Leonardo Palmisano

\begin{abstract}
Phenol (PH) and three polynitrophenols (4-nitrophenol (PNP), 2,4-dinitrophenol (DNP), 2,4,6-trinitrophenol (TNP)) were photocatalytically degraded by using titania under either artificial or solar light. These four reactions were chosen as test reactions to compare the efficiencies of two suspended commercial titania photocatalysts (Degussa P-25 and Millennium PC-500). It appears that P-25 has a higher initial efficiency in all nitrophenol disappearance reactions. However, for the overall degradation rate, measured by the chemical oxygen demand (COD) disappearance, the performance of PC-500 was similar to that of P25. This was attributed to a favorable textural effect since PC-500 has a much higher surface area which facilitates the readsorption of intermediates. PC-500 was subsequently supported on a special photoinert paper provided by Ahlstrom Company (38-Pont Evèque, France). The influence of the silica binder used for sticking titania particles on the paper fibers was put in evidence as an inhibitor of the coulombic adsorption of anionic species, especially 2,4,6-trinitrophenol, because of the low pzc of silica. Once validated, this supported photocatalyst was introduced in an autonomous solar pilot photoreactor identical to the several prototypes built in the European AQUACAT program. It was demonstrated that the purification of water could be efficiently obtained in a larger scale without any final tedious filtration.
\end{abstract}

Copyright (c) 2008 Hinda Lachheb et al. This is an open access article distributed under the Creative Commons Attribution License, which permits unrestricted use, distribution, and reproduction in any medium, provided the original work is properly cited.

\section{INTRODUCTION}

The photocatalytic degradation of toxic compounds in aqueous medium provides a new opportunity for the treatment of urban and agricultural wastewater. Nitrophenols, for example, are released into the environment because of their wide use in syntheses of dyes, pesticides, plasticizers, and solvents. In addition, they are formed as degradation products of many chemicals such as herbicides (see for instance herbicides nitrofen [1] and parathion [2]) when they are exposed to sunlight [3]. The photocatalytic degradation rate of the different nitrophenols depends on various parameters, such as temperature [4], $\mathrm{pH}[4,5]$, initial concentration of the pollutant [4-6], and light intensity. Various studies have shown that the number and positions of substituent in some aro- matic compounds are widely linked to their photocatalytic reactivity [7-11].

Advanced oxidation processes (AOPs) have been proposed as an alternative for the treatment of wastewater containing nitrophenols. A lot of studies focused on these processes [12-16] have pointed out that, although the reacting systems were different $[17,18]$, they are all characterized by the same chemical feature, that is, the production of $\mathrm{OH}^{\circ}$ radicals, which as the second best oxidant after fluorine, is the active species responsible for the destruction of organic pollutants $[19,20]$.

The objective of this study was the validation of the performances of two commercial catalysts using the photocatalytic degradation of polynitrophenols, (4-nitrophenol (PNP), 2,4-dinitrophenol (DNP), and 2,4,6-trinitrophenol 
TABLE 1: Physicochemical characteristics of polynitrophenols.

\begin{tabular}{lcccc}
\hline Compound & $\mathrm{Mw}(\mathrm{g} / \mathrm{mol})$ & $\lambda_{\max }(\mathrm{nm})$ & $\varepsilon\left(\mathrm{L} \cdot \mathrm{mg}^{-1} \cdot \mathrm{cm}^{-1}\right)$ & $\mathrm{pKa}$ \\
\hline Phenol & 94.11 & 270 & 0.0153 & $\mathrm{pH}$ \\
4-nitrophenol (PNP) & 139.11 & 317 & 0.0623 & 6.20 \\
2,4-dinitrophenol (DNP) & 184.11 & 260 & 0.0560 & 7.16 \\
2,4,6-trinitrophenol (TNP) & 229.11 & 356 & 0.0461 & 5.8 \\
\hline
\end{tabular}

TABLE 2: Langmuir parameters of phenolic compound adsorption.

\begin{tabular}{|c|c|c|c|c|c|c|c|c|}
\hline \multirow[t]{2}{*}{ Reactants } & \multicolumn{3}{|c|}{ Degussa P25 } & \multicolumn{3}{|c|}{ PC500 } & \multicolumn{2}{|c|}{ PC500/Paper 1048} \\
\hline & $q_{\max }(\mathrm{mg} / \mathrm{g})$ & $K_{\mathrm{ads}}(\mathrm{L} / \mathrm{mg})$ & $n_{\mathrm{ads}}\left(\mathrm{mol} / \mathrm{nm}^{2}\right)$ & $q_{\max }(\mathrm{mg} / \mathrm{g})$ & $K_{\text {ads }}(\mathrm{L} / \mathrm{mg})$ & $n_{\text {ads }}\left(\mathrm{mol} / \mathrm{nm}^{2}\right)$ & $q_{\max }(\mathrm{mg} / \mathrm{g})$ & $K_{\text {ads }}(\mathrm{L} / \mathrm{mg})$ \\
\hline Phenol & 4.87 & 0.031 & 0.62 & 6.27 & 0.136 & 0.125 & 10.44 & 0.290 \\
\hline 4-nitrophenol (PNP) & 10.25 & 0.046 & 0.88 & 9.11 & 0.290 & 0.120 & 8.32 & 0.217 \\
\hline 2,4-dinitrophenol (DNP) & 15.52 & 0.025 & 1.00 & 11.73 & 0.110 & 0.120 & 6.60 & 2.780 \\
\hline 2,4,6-trinitrophenol (TNP) & 18.93 & 0.020 & 1.00 & 15.86 & 0.021 & 0.130 & 5.66 & 7.00 \\
\hline
\end{tabular}

$n_{\text {ads }}$ : area density of adsorbed phenol molecules (in molecules $/ \mathrm{nm}^{2}$ ).

(TNP) or picric acid (TNP)) as test reactions. Such degradations are now well known $[4-6,17,18,21]$. These reactions were performed in presence of powder or of supported $\mathrm{TiO}_{2}$. In the last case, we used Millennium PC500 titania coated on an Ahlstrom nonwoven paper to validate its performances. Subsequently, this deposited photocatalyst was used in an "AQUACAT" pilot solar photoreactor to clean and reuse contaminated water in semiarid areas. This is in line with the pioneer works performed at Plataforma Solar de Almeria (PSA) on many pollutants [22-25].

\section{EXPERIMENTAL}

\subsection{Materials and reagents}

Titanium dioxide Degussa P-25 was used as the reference photocatalyst. It is constituted of $80 \%$ anatase and $20 \% \mathrm{ru}-$ tile and its BET surface area is $50 \mathrm{~m}^{2} / \mathrm{g}$, corresponding to a mean particle size of $c a .30 \mathrm{~nm}$. Millennium PC500 titanium dioxide (100\% anatase, specific surface area of $320 \mathrm{~m}^{2} / \mathrm{g}$ ) was also used either as a powder in slurry or supported on a nonwoven paper (paper Ahlstrom 1048), offerred by Mr. J. Dussaud from Ahlstrom Company. The area loading in $\mathrm{TiO}_{2}$ was $18 \mathrm{~g} / \mathrm{m}^{2}$. Supported titania has been tested by using either UV artificial light in laboratory experiments or solar light for outside experiments in South Tunisia . The phenolic compounds were purchased from Aldrich (38-Ville D'Abeau, France) and used as received without further purification. Their solutions were prepared using twice-distilled water. Their physicochemical characteristics are given in Table 1.

\subsection{Apparatus}

A one-liter reactor was used in the laboratory experiments. It is equipped with a plunging tube in which a Philips HPK $125 \mathrm{~W}$ UV-lamp was placed vertically. To avoid the heating of the solution, water was circulated through a cylindrical jacket, made of Pyrex and located around the plunging tube.

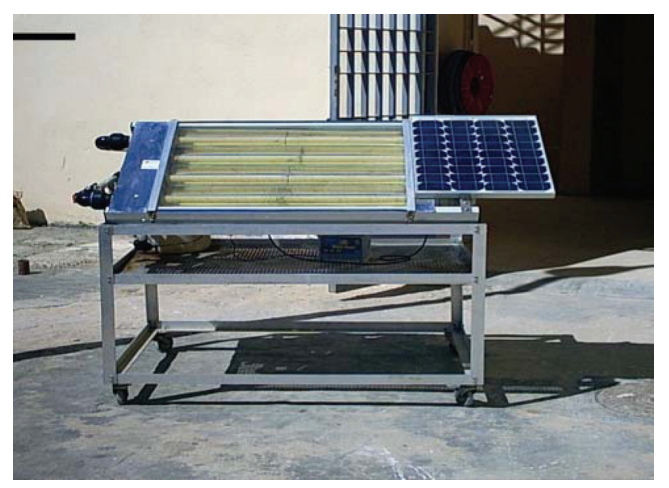

FIGURE 1: Photograph of the autonomous AQUACAT solar pilot prototype.

The photon flux of the UV irradiation reaching the exposed inner part of the reactor at $\lambda>290 \mathrm{~nm}$ was measured to be around $6 \cdot 10^{-6}$ Einstein (mol of photons) per second. Another photoreactor was employed for solar experiments. It is an autonomous pilot scale prototype developed by the European Research Project AQUACAT using $\mathrm{TiO}_{2}$ supported on Ahlstrom paper 1048 (Figure 1). This new photoreactor was employed for solar experiments and consists of one sun collector, one water tank, and one electrical circulating pump connected with a photovoltaic panel. The reactor itself consists of glass tubes connected in series and placed on a fixed platform inclined at a $37^{\circ}$ angle corresponding to the local latitude for collecting a maximum solar irradiation around noon. The water circulating flow was fixed at $12 \mathrm{~L} / \mathrm{min}$. The total volume $\left(V_{T}\right)$ of the water treated was $20 \mathrm{~L}$ and divided in $12 \mathrm{~L}$ in the irradiated glass tubes and $8 \mathrm{~L}$ in the tank. This pilot plantis a plug-flow reactor connected to a tank with recirculation. This ensemble corresponds to a batch reactor. During experiments, the temperature of the effluent varied in the range of $35-40^{\circ} \mathrm{C}$, that is, close to the optimum for photocatalysis $[19,20]$. 
TABLE 3: Kinetic data of the photocatalytic degradation of nitrophenols.

\begin{tabular}{llllllllll}
\hline \multicolumn{2}{c}{ P25 } & \multicolumn{3}{c}{ PC500 } \\
\hline & $\begin{array}{l}K_{\text {app }} \cdot 10^{2} \\
\left(\mathrm{mn}^{-1}\right)\end{array}$ & $\begin{array}{l}K_{\mathrm{app}} / \mathrm{g} \cdot 10^{2} \\
\left(\mathrm{mn}^{-1} \cdot \mathrm{g}^{-1}\right)\end{array}$ & $\begin{array}{l}\text { ro } \\
(\mathrm{ppm} / \mathrm{min})\end{array}$ & $\begin{array}{l}K_{\mathrm{app}} \cdot 10^{2} \\
\left(\mathrm{mn}^{-1}\right)\end{array}$ & $\begin{array}{l}K_{\mathrm{app}} / \mathrm{g} \cdot 10^{2} \\
\left(\mathrm{mn}^{-1} \cdot \mathrm{g}^{-1}\right)\end{array}$ & $\begin{array}{l}\text { ro } \\
(\mathrm{ppm} / \mathrm{min})\end{array}$ & $\begin{array}{l}K_{\text {app }} \cdot 10^{2} \\
\left(\mathrm{mn}^{-1}\right)\end{array}$ & $\begin{array}{l}K_{\text {app }} \cdot 10^{2} \\
\left(\mathrm{mn}^{-1} \cdot \mathrm{g}^{-1}\right)\end{array}$ & $\begin{array}{l}\text { ro } \\
\left(\mathrm{ppm} / \mathrm{min}^{2}\right.\end{array}$ \\
\hline PH & 0.56 & 1.12 & 0.093 & 0.53 & 1.06 & 0.13 & 0.92 & 1.08 & 0.11 \\
PNP & 1.00 & 2.00 & 0.184 & 0.73 & 1.46 & 0.16 & 0.67 & 0.78 & 0.10 \\
DNP & 1.18 & 2.36 & 0.240 & 0.96 & 1.92 & 0.18 & 0.48 & 0.56 & 0.06 \\
TNP & 1.98 & 3.96 & 0.298 & 1.28 & 2.56 & 0.24 & 0.33 & 0.38 & 0.05 \\
\hline
\end{tabular}

TABLE 4: Initial COD values in $\mathrm{mgO}_{2} / \mathrm{L}$ for nitrophenols having the same initial ponderal concentration (30 mg/L). Apparent first-order rate constant $K_{\text {app }}$ and corresponding specific one $K_{\text {app }} / g_{\text {cat }}$.

\begin{tabular}{|c|c|c|c|c|c|c|c|}
\hline & \multirow[t]{2}{*}{ COD initial $(\mathrm{mg} / \mathrm{L})$} & \multicolumn{2}{|r|}{$\mathrm{P} 25$} & \multicolumn{2}{|c|}{ PC500 } & \multicolumn{2}{|c|}{ Paper 1048} \\
\hline & & $\begin{array}{l}K_{\text {app }} \\
\left(\mathrm{mn}^{-1}\right)\end{array}$ & $\begin{array}{l}K_{\text {app }} / \mathrm{g} \\
\left(\mathrm{mn}^{-1} \cdot \mathrm{g}^{-1}\right)\end{array}$ & $\begin{array}{l}K_{\text {app }} \\
\left(\mathrm{mn}^{-1}\right)\end{array}$ & $\begin{array}{l}K_{\text {app }} / g \\
\left(\mathrm{mn}^{-1} \cdot \mathrm{g}^{-1}\right)\end{array}$ & $\begin{array}{l}K_{\text {app }} \\
\left(\mathrm{mn}^{-1}\right)\end{array}$ & $\begin{array}{l}K_{\text {app }} / g \\
\left(\mathrm{mn}^{-1} \cdot \mathrm{g}^{-1}\right)\end{array}$ \\
\hline Phenol (PH) & 74 & 0.50 & 1.0 & 1.15 & 2.30 & 0.80 & 0.94 \\
\hline 4-nitrophenol (PNP) & 50 & 0.80 & 1.6 & 1.73 & 3.46 & 1.12 & 1.31 \\
\hline 2,4-dinitrophenol (DNP) & 45 & 1.28 & 2.5 & 2.19 & 4.38 & 1.66 & 1.95 \\
\hline 2,4,6-trinitrophenol (TNP) & 30 & 1.84 & 3.7 & 3.14 & 6.28 & 3.62 & 4.25 \\
\hline
\end{tabular}

TABLE 5: Solar degradation and mineralization kinetics $\left(K_{\mathrm{app}}, r_{0}\right)$ of phenolic compounds.

\begin{tabular}{lcccc}
\hline & \multicolumn{2}{c}{$K_{\text {app }} \cdot 10^{2}\left(\mathrm{mn}^{-1}\right)$} & \multicolumn{2}{c}{$r_{0}(\mathrm{~mol} / \mathrm{L} \cdot \mathrm{min})$} \\
\hline Phenol & Degradation & Mineralization & Degradation & Mineralization \\
4-nitrophenol (PNP) & 0.17 & 0.15 & 0.068 & 0.066 \\
2,4-dinitrophenol (DNP) & 0.42 & 0.23 & 0.105 & 0.083 \\
2,4,6-trinitrophenol (TNP) & 0.28 & 0.45 & 0.080 & 0.108 \\
\hline
\end{tabular}

\subsection{Procedure}

\subsubsection{Laboratory experiments}

One liter of aqueous solution of each phenolic compound $\left(\mathrm{C}_{0}=30 \mathrm{mg} / \mathrm{L}\right)$ was introduced into the lab reactor and an amount of $500 \mathrm{mg}$ of $\mathrm{TiO}_{2}$ (P25 or PC500) was added to get a final concentration of $0.5 \mathrm{~g} / \mathrm{L}$. The same photoreactor was used with $\mathrm{PC} 500-\mathrm{TiO}_{2}$ photocatalyst supported on Ahlstrom paper 1048. A sheet of this titania supporting paper was deposited on a glass cylinder of $12.5 \mathrm{~cm}$ in diameter and $12 \mathrm{~cm}$ high. The corresponding concentration of $\mathrm{TiO}_{2}$ was about $850 \mathrm{mg} / \mathrm{L}$. The degradation reactions were carried out at $293 \mathrm{~K}$ and at natural $\mathrm{pH}$ values $(6.7,5.8,5.3$, and 4.0, for phenol, PNP, DNP, and TNP, resp.). The suspension was first stirred in the dark for 90 minutes before irradiation in order to reach the adsorption equilibrium before starting the photocatalytic reaction.

\subsubsection{Solar experiments}

The total volume $\left(V_{T}\right)$ treated was $20 \mathrm{~L}$ and the water flow rate was fixed at $12 \mathrm{~L} / \mathrm{min}$. The suspension was first stirred in the dark for 90 minutes before irradiation to reach equilibrated adsorption. Stirring was obtained by recirculating the total volume of $20 \mathrm{~L}$ at a flow rate of $12 \mathrm{~L} / \mathrm{min}$ obtained by the electrical pump run by the photovoltaic panel. As for laboratory experiments, the initial concentration of phenols was fixed at $30 \mathrm{mg} / \mathrm{L}$.

\subsection{Analyses}

Before analysis, the aqueous samples were filtered through a $0.45 \mu \mathrm{m}$ membrane filter to remove $\mathrm{TiO}_{2}$ agglomerates in suspension. A Schimadzu-1700 UV-vis spectrophotometer was used to determine the concentration of the nitrophenols and to follow their kinetic disappearance. Calibration plots based on Beer-Lambert's law were established to relate the absorbance to the concentration. The molar extinction coefficients for phenol, 4-nitrophenol (PNP), 2,4-dinitrophenol (DNP), and 2,4,6-trinitrophenol (TNP) were estimated at $270,317,260$, and $356 \mathrm{~nm}$, respectively. Chemical oxygen demand (COD) was measured using the acidic dichromate method with a bioblock COD analyzer.

\section{RESULTS AND DISCUSSION}

\subsection{Adsorption of phenolic compounds on titania}

The adsorption of the different phenolic compounds is studied at room temperature $\left(20 \pm 2^{\circ} \mathrm{C}\right)$ and at natural $\mathrm{pH}$. The 


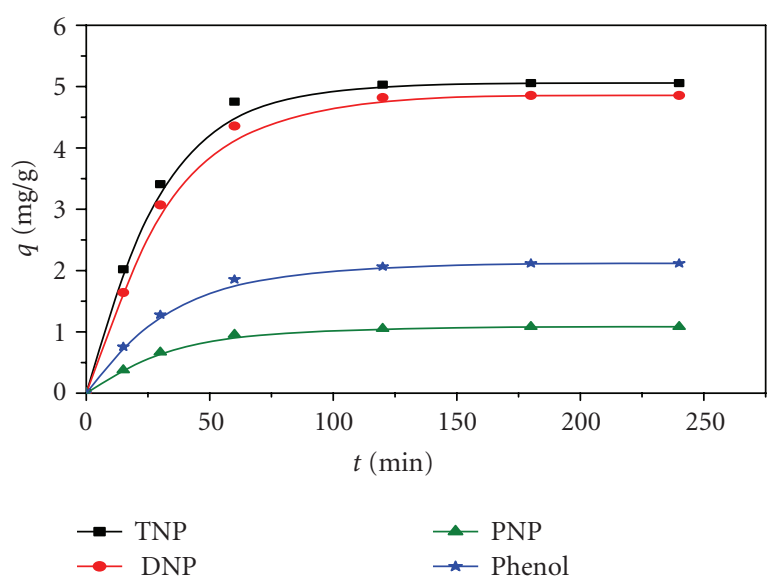

(a)

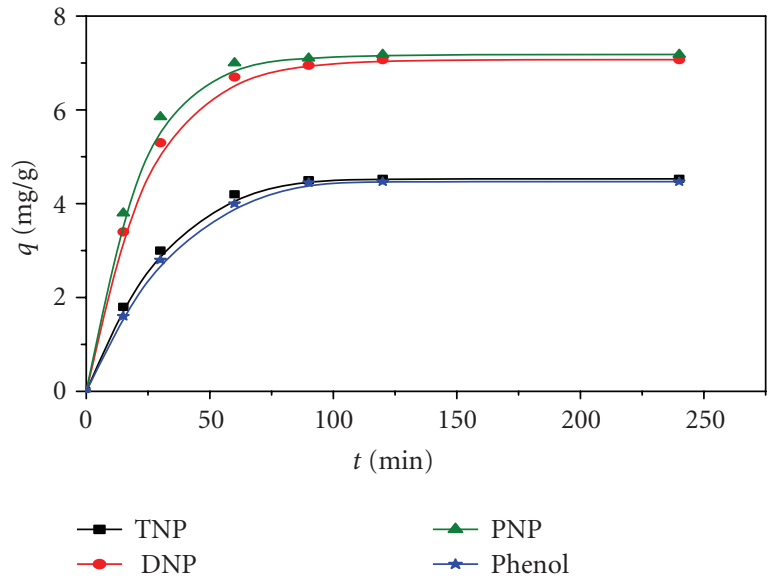

(b)

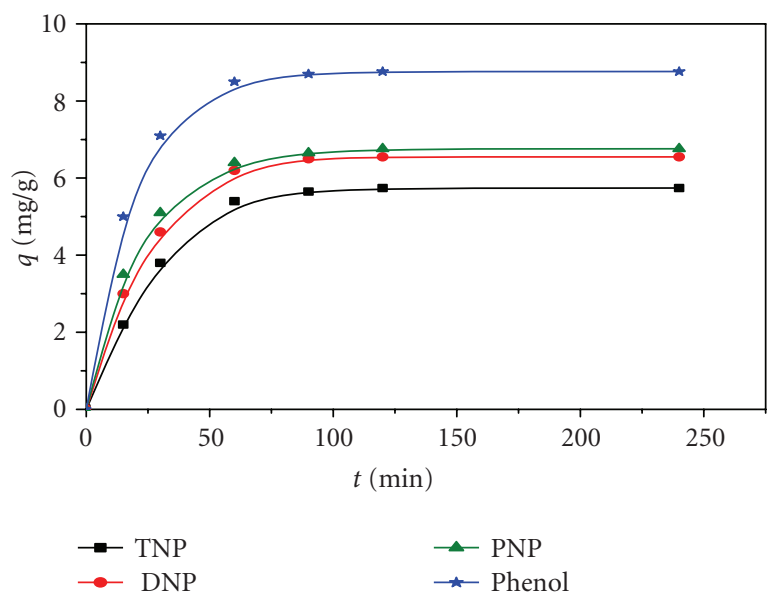

(c)

FIGURE 2: Kinetics of adsorption of phenolic compounds in presence of different catalysts (a). Degussa P25, (b) Millennium PC500, and (c) Millennium PC-500 $\mathrm{TiO}_{2}$ deposited on Ahlstrom paper 1048. Experimental conditions: $\mathrm{C}_{0}=30 \mathrm{mg} / \mathrm{L},[\mathrm{P} 25]=[\mathrm{PC} 500]$ $=2.5 \mathrm{~g} / \mathrm{L}, \mathrm{V}=100 \mathrm{~mL}$, natural $\mathrm{pH}$.

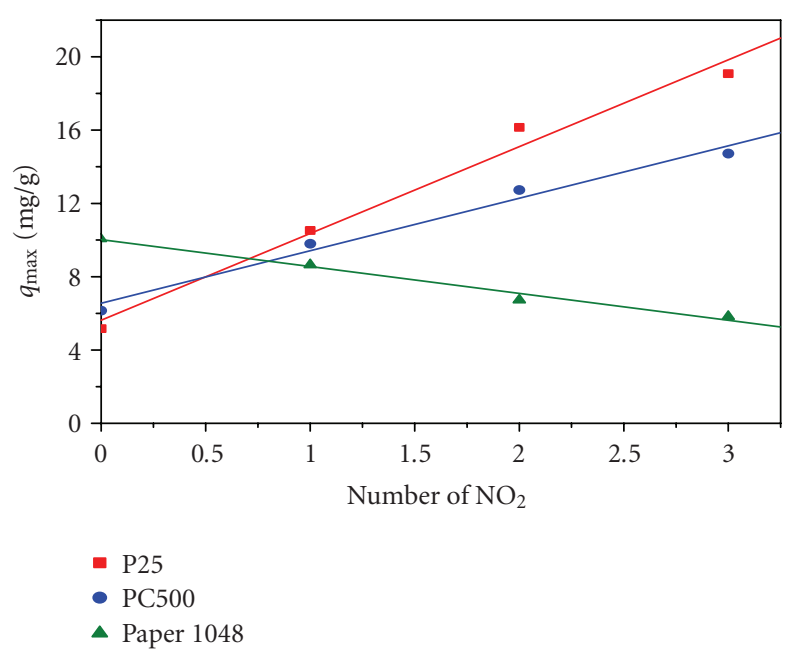

FIGURE 3: Linear variations between the maximum quantity of adsorbed polynitrophenols $q_{\max }$ and the number of $\mathrm{NO}_{2}$ substituent.

adsorption kinetic curves for the four phenolic compounds (phenol, PNP, DNP, and TNP) on different catalysts are represented in Figure 2. The initial concentration is fixed at $30 \mathrm{mg} / \mathrm{L}$. For each phenolic compound, whatever the catalyst employed, the steady state of adsorption is reached within 90 minutes. Therefore, this time has been selected as the duration of the dark period previously to irradiation. The degradation initiates at the equilibrium of adsorption. The maximum absorbed quantities $q_{\max }$ and the adsorption constants $K_{\mathrm{ads}}$ of phenols were determined at different initial concentrations varying between 5 and $30 \mathrm{mg} / \mathrm{L}$ using the linear transform of the Langmuir equation,

$$
\frac{C_{e}}{q_{e}}=\frac{1}{K q_{\max }}+\frac{C_{e}}{q_{\max }}
$$

where $C_{e}$ is the equilibrium concentration of the phenolic compounds and $q_{e}$ is the quantity of the adsorbed phenolic compounds at $\mathrm{TiO}_{2}$ surface. The linearity of the curves clearly indicates that the Langmuir isotherm is correctly observed, implying a monolayer adsorption model. The calculated values are listed in Table 2.

The following general observations can be made. For both unsupported Degussa P25 and Millennium PC-500 photocatalysts, the maximum quantities of adsorbed phenolic compounds increase in the following order:

$$
\text { Phenol }<\text { PNP }<\text { DNP }<\text { TNP. }
$$

This is in line with an ionic type of adsorption. Because of their decreasing pKa's and of the resulting pH's of the solutions, the surface of titania samples gets positively charged according to

$$
\mathrm{Ti}-\mathrm{OH}+\mathrm{H}^{+} \rightleftarrows \mathrm{Ti}-\mathrm{OH}_{2}{ }^{+} .
$$

This favors the coulombic attraction and the related adsorbed quantities of the nitrophenols. 


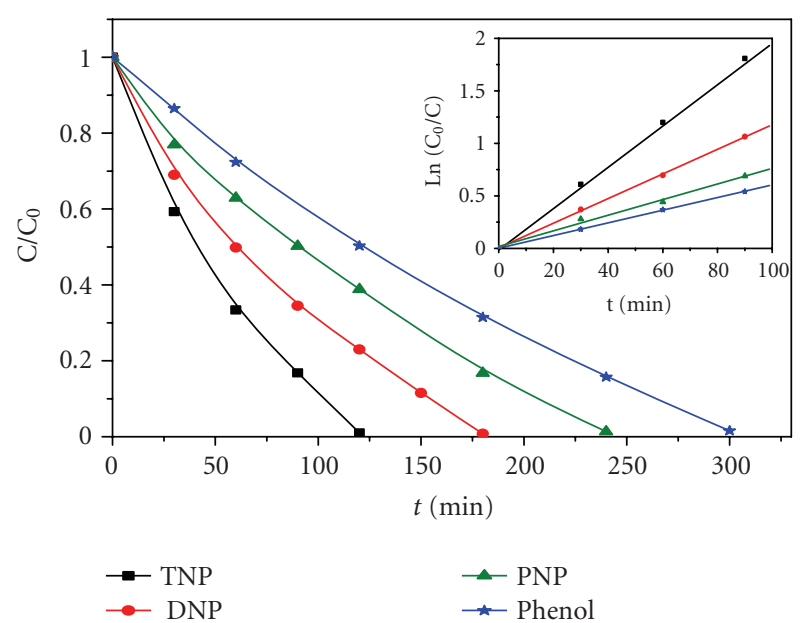

(a)

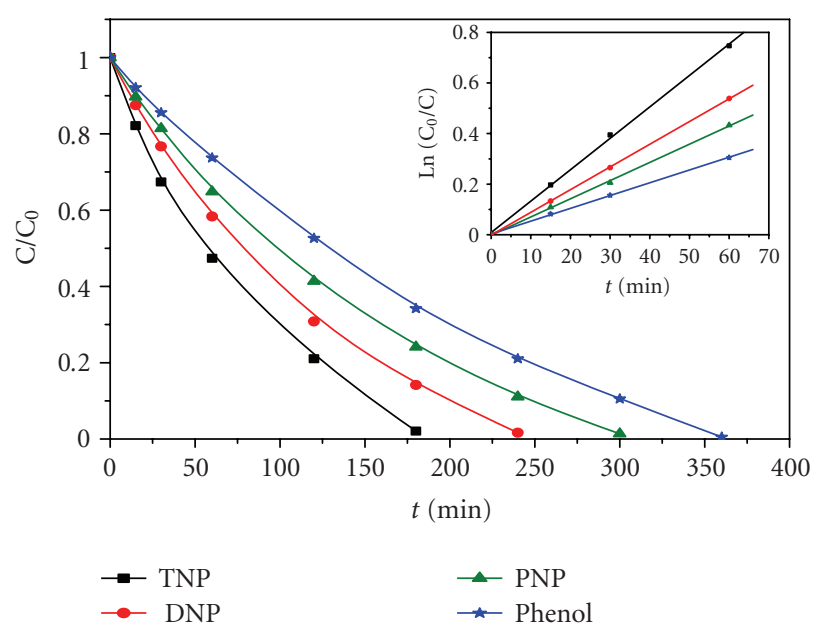

(b)

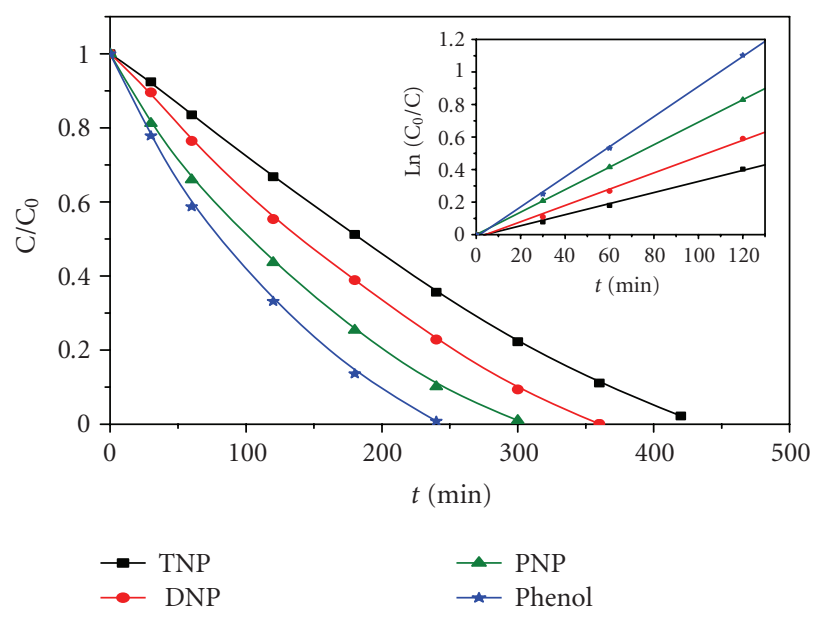

(c)

FIgURE 4: Kinetics of the photocatalytic degradation of phenols in presence of different catalysis ((a) P25, (b) PC500, and (c) supported $\mathrm{TiO}_{2}$ (paper 1048)). In the insert, first-order linear transforms $\mathrm{Ln} \mathrm{C}_{0} / \mathrm{C}=f(t)$. Experimental conditions: $\mathrm{C}_{0}=30 \mathrm{mg} / \mathrm{L}$, $[\mathrm{P} 25]=[\mathrm{PC} 500]=0.5 \mathrm{~g} / \mathrm{L}, \mathrm{V}=1 \mathrm{~L}$, natural $\mathrm{pH}$.

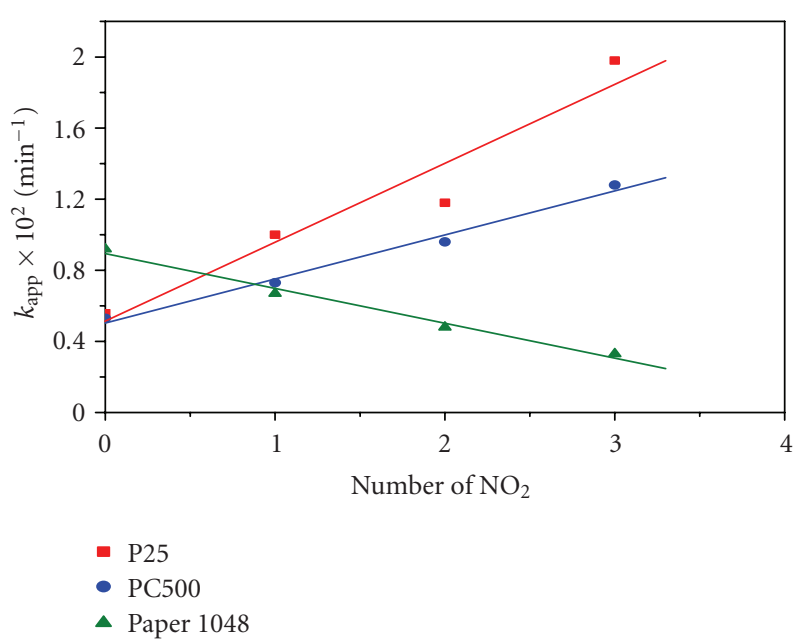

FIGURE 5: Linear variations of the rate constants with the number of $\mathrm{NO}_{2}$ substituents.

By contrast, the variations of $q_{\max }$ are opposite for PC500/paper 1048. This is due to the presence of the amorphous silica binder. Since the pzc of silica is very low in comparison with that of titania (56), there is a coulombic repulsion of the anionic polynitrophenols by the negatively charged together (silica binder + titania catalyst). Surprisingly, there is a proportional variation between $q_{\max }$ and the number $n$ of nitrosubstituents as illustrated in Figure 3.

\subsection{Photocatalytic degradation of the polynitrophenols}

The disappearance rates of nitrophenolic compounds in contact with the three UV-irradiated photocatalysts are given in Figure 4. Starting with an initial concentration of $30 \mathrm{mg} / \mathrm{L}$, the total disappearance of all nitrophenolic compounds is reached in between 2 and 7 hours.

All reactions followed an apparent first-order verified by the linear transforms $\operatorname{Ln}\left(\mathrm{C}_{0} / \mathrm{C}\right)=f(t)$ illustrated in the insert in Figure 5. The slopes give the apparent rate constants listed in Table 3. The initial rates of disappearance in $\mathrm{ppm} / \mathrm{min}$ are in the following order: TNP $>$ DNP $>$ PNP $>$ phenol. It appears that PC500 is less efficient for the photocatalytic disappearance of nitrophenols than P25. This also observed for specific activities, that is, rates per $\mathrm{g}$ of catalyst (see Table 3). For PC500 supported on Ahlstrom paper 1048, the order is different-phenol $<\mathrm{PNP}<\mathrm{DNP}<\mathrm{TNP}$.

All these differences can be explained by considerations about adsorption. The rates of polynitrophenol disappearance vary in parallel with the quantities of adsorbed pollutants as indicated by the corresponding parameters indicated in Tables 2 and 3. In addition, this is confirmed by the parallel proportional variations of either the quantities of polynitrophenols adsorbed (Figure 3 ) or of the rate constants as function of the number of $\mathrm{NO}_{2}$ groups (Figure 5). This confirms the Langmuir-Hinshelwood mechanism involved in these reactions. 


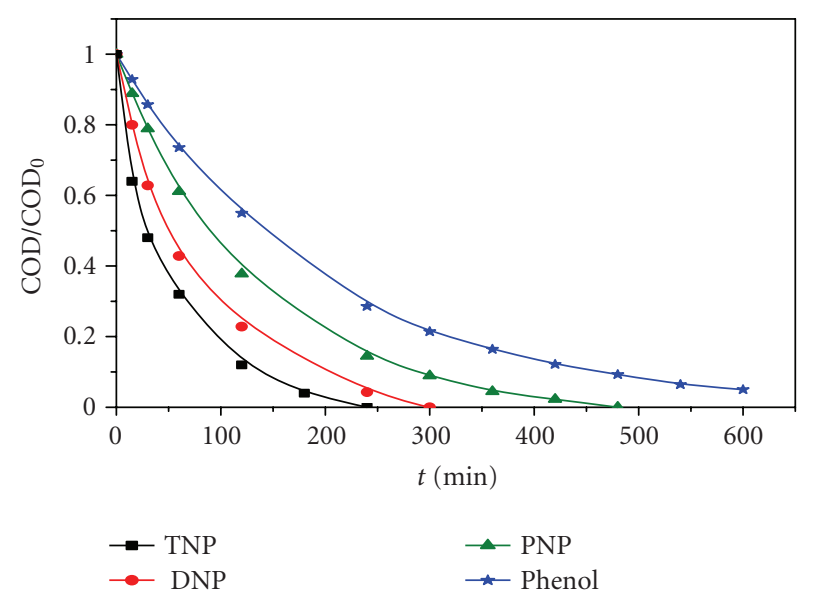

(a)

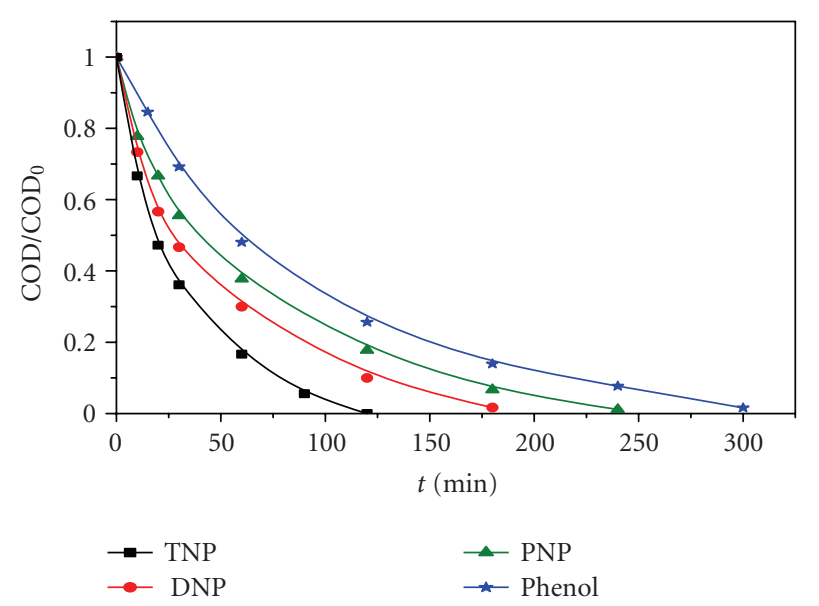

(b)

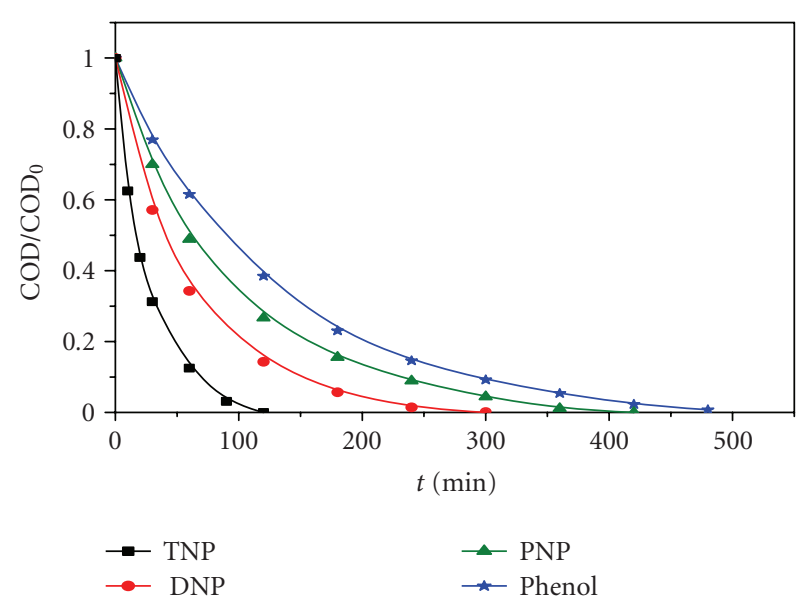

(c)

FIGURE 6: Kinetics of COD disappearance of nitrophenols in presence of different catalysts ((a) Degussa P25, (b) Millennium PC500, and (c) PC-500 supported on Ahlstrom paper 1048). Experimental conditions: $\mathrm{C}_{0}=30 \mathrm{mg} / \mathrm{L},[\mathrm{P} 25]=[\mathrm{PC} 500]=0.5 \mathrm{~g} / \mathrm{L}, \mathrm{V}=$ $1 \mathrm{~L}$, natural $\mathrm{pH}$.

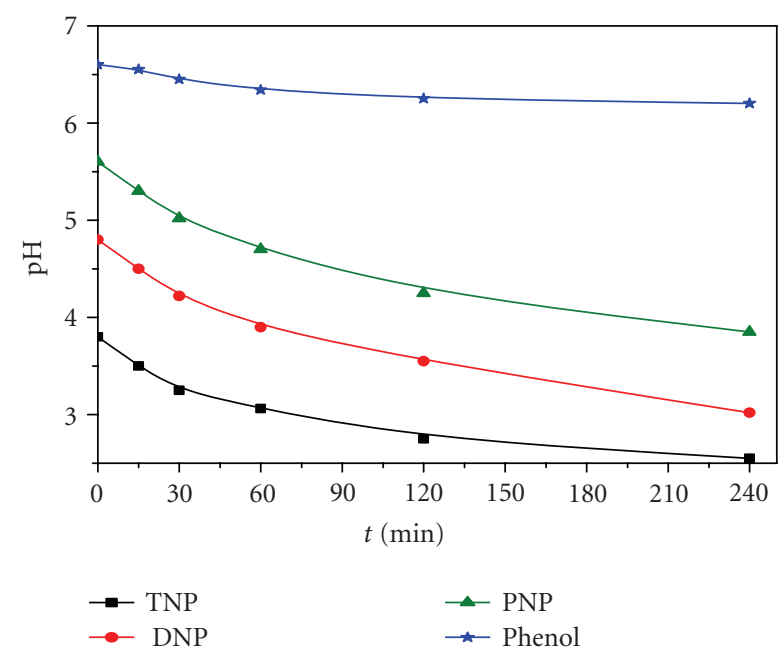

FIGURE 7: Kinetics of $\mathrm{pH}$ variations during the photocatalytic degradation of nitrophenols. Experimental conditions: $\mathrm{C}_{0}=30 \mathrm{mg} / \mathrm{L}$, $[\mathrm{P} 25]=[\mathrm{PC} 500]=0.5 \mathrm{~g} / \mathrm{L}, \mathrm{V}=1 \mathrm{~L}$

\subsection{Kinetics of COD disappearance}

The kinetics of the total mineralization of nitrophenols has been determined by following the disappearance of the chemical oxygen demand (COD). The kinetic isotherms are given in Figure 6. For all nitrophenols, COD reached 0 within 8 hours. The initial values of COD are in agreement with the chemical formulas and with the stoichiometries of all nitrophenols degradation reaction, TNP having the smallest COD.

Although titania Degussa P-25 has the highest activity for nitrophenols disappearance, it clearly appears from Table 4 that PC-500 has an important efficiency in their total mineralization. This can be explained by a favorable textural effect. Since total degradation involves many consecutive reactions before reaching $\mathrm{CO}_{2}$, the readsorption of all the numerous intermediates is favored by catalyst having large surface areas, which is the case of PC-500.This advantage can be transposed to PC-500 supported on paper Ahlstrom 1048, as seen from data in Table 4. This underlines the interest of using supported catalyst to decontaminate wastewater by avoiding the tedious final filtration step, which strongly increases the overall cost of this potential treatment.

\subsection{Kinetics of $p H$ variations during the degradation of phenols}

According to the stoichiometry of the total oxidation reaction,

$$
\begin{aligned}
& \left(\mathrm{NO}_{2}\right)_{x}-\mathrm{C}_{6} \mathrm{H}_{(5-x)}-\mathrm{OH}+7 \mathrm{O}_{2} \\
& \quad \longrightarrow 6 \mathrm{CO}_{2}+x \mathrm{NO}_{3}^{-}+x \mathrm{H}^{+}+(3-x) \mathrm{H}_{2} \mathrm{O}
\end{aligned}
$$

the $\mathrm{pH}$ of the reaction medium is expected to decrease except for phenol $(x=0)$. This is actually observed with its temporal variations given in Figure 7. Therefore, the kinetics of $\mathrm{pH}$ variations is a good indicator of nitrophenols degradation or, at least, of their denitration. However, $\mathrm{pH}$ in the 
<smiles>Oc1ccccc1</smiles>

Phenol<smiles>O=[N+]([O-])c1ccc(O)cc1</smiles>

4-nitrophenol (PNP)<smiles>O=[N+]([O-])c1ccc(O)c([N+](=O)[O-])c1</smiles>

2.4-dinitrophenol (DNP)<smiles>O=[N+]([O-])c1cc([N+](=O)[O-])c(O)c([N+](=O)[O-])c1</smiles>

2.4.6-trinitrophenol (TNP)

Scheme 1

UV-irradiated titania slurry is a rather important and complex parameter since it governs (i) water dissociation equilibrium, (ii) the surface charge of titania with respect to its pzc, and (iii) the ionization state of the organic reactants and of their intermediates. In addition, it also depends on the degradation of other pollutants present in the water to be treated. Nevertheless, in a batch photoreactor, its steady-state final value could be an easy and cheap indicator of the final reaching of total mineralization.

\subsection{Solar experiments in the autonomous pilot plant}

The polynitrophenol degradation reactions have been transposed to the solar pilot photoreactor and used to determine the efficiency of supported PC500 $\mathrm{TiO}_{2}$ using solar energy in South Tunisia. This pilot plantis a plug-flow reactor connected to a tank with recirculation. This ensemble corresponds to a batch reactor. Because of the design of the reactor and of the varying solar radiant flux, a direct comparison with the results obtained in laboratory would not be correct. Only basic fundamental features are comparable for laboratory and pilot results. Actually, all reactions followed an apparent first-order kinetics, confirmed by the linear transforms Ln $\mathrm{C}_{0} / \mathrm{C}=f(t)$ in the inserts in Figure 8. The rate constants of the disappearance of nitrophenols are in a similar order of reactivity, $\mathrm{PNP}>\mathrm{DNP}>$ phenol $>$ TNP. The kinetic parameters of COD disappearance, which are illustrated by Figure 9 and listed in Table 5 show that TNP has the higher rate of COD disappearance as in laboratory experiments.

\section{CONCLUSIONS}

The photocatalytic degradation reactions of phenol and of mono-, di-, and trinitrophenol, chosen as test reactions to compare the efficiencies of two suspended commercial titania photocatalysts (Degussa P-25 and Millennium PC500), underlined the difficulty and complexity in objectively comparing two solids. If Degussa P-25 appeared easily as that having the higher initial efficiency in all nitrophenol disappearance reactions (as mostly observed in literature), however, for the overall degradation rate, measured by the chemical oxygen demand (COD) disappearance, the performances of PC-500 were similar to its own ones. This was attributed to

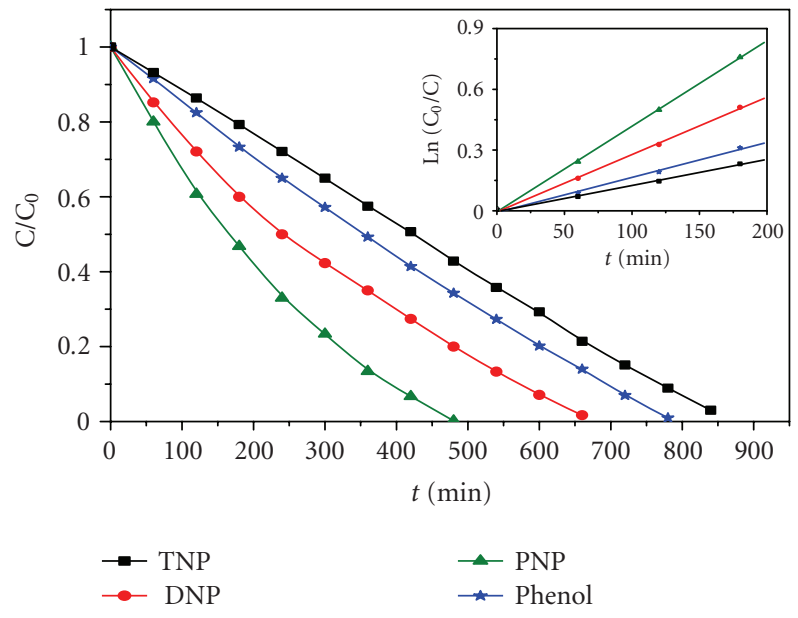

FIGURE 8: Experiments with pilot plant using solar energy, phenols disappearance. In the insert: first-order linear transforms $\mathrm{Ln} \mathrm{C}_{0} / \mathrm{C}$ $=f(t)$ of nitrophenols degradation. Experimental conditions: $\mathrm{C}_{0}=$ $30 \mathrm{mg} / \mathrm{L}, \mathrm{V}=20 \mathrm{~L}$, TiO2 supported on Ahlstrom paper 1048, natural $\mathrm{pH}$.

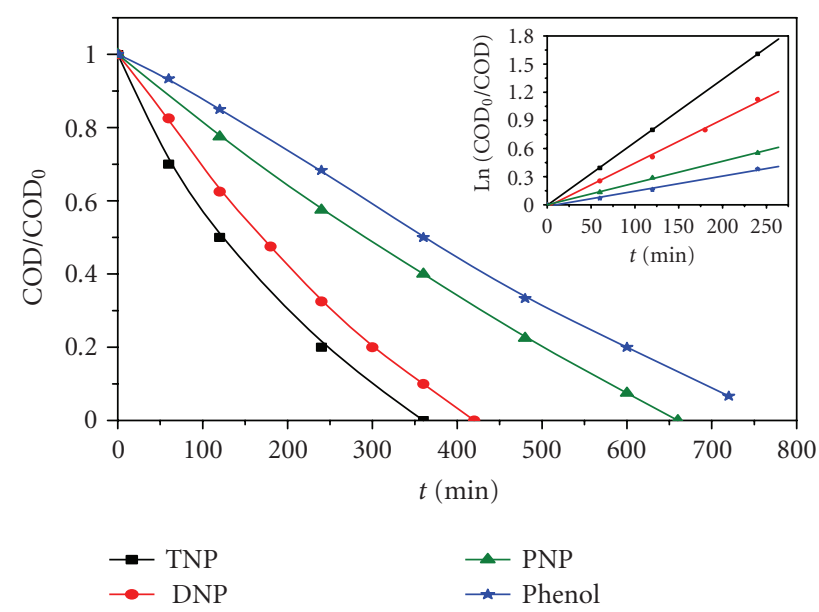

FIGURE 9: Experiments with pilot plant using solar energy, Kinetics of COD disappearance, in the insert: first-order linear transforms Ln $\left(\mathrm{COD}_{0}\right) / \mathrm{COD}=f(t)$ of nitrophenols mineralization. Experimental conditions: $\mathrm{C}_{0}=30 \mathrm{mg} / \mathrm{L}, \mathrm{V}=20 \mathrm{~L}$, supported $\mathrm{TiO}_{2}$ (paper 1048), natural $\mathrm{pH}$. 
a favorable textural effect since PC-500 has a much higher surface area, which facilitates the readsorption of the very large number of intermediates. When PC-500 was subsequently supported on a special photoinert paper provided by Ahlstrom Company, the presence of the silica binder, used for sticking titania particles on the paper fibers, perturbs several key parameters, principally the natural $\mathrm{pH}$, because of the low pzc of silica. It acts as an inhibitor of the coulombic adsorption of anionic species, especially, 2,4,6trinitrophenol. However, despite this negative influence, the supported photocatalyst when introduced in an autonomous AQUACAT solar pilot photoreactor clearly demonstrates that it can achieve purification of water with a reasonable efficiency, very compatible with the use of solar energy at a larger scale. In particular, it avoids the final tedious filtration necessary (i) to provide clean water and (ii) to recover and recycle the catalysts. Since filtration is declared as redhibitory by the chemical engineering point of view, this stresses the usefulness of such a material.

\section{ACKNOWLEDGMENTS}

The authors thank the European Commission (Research DG) for its financial support within confirming the international role of Community Research for Development (INCO-DEV). Project ICA3-CT2002-10016 "AQUACAT". The authors also wish to thank Dr J. Dussaud from Ahlstrom Research and Services for supplying the photocatalytic nonwoven paper.

\section{REFERENCES}

[1] M. Nakagawa and D. G. Crosby, "Photonucleophilic reactions of nitrofen," Journal of Agricultural and Food Chemistry, vol. 22, no. 6, pp. 930-933, 1974.

[2] P. Méallier, J. Nury, B. Pouyet, C. Coste, and J. Bastide, "Photodegradation des molecules phytosanitaires II-cinetque et mecanisme de photodegradation du parathion," Chemosphere, vol. 6, no. 12, pp. 815-820, 1977.

[3] S. Parra, J. Olivero, L. Pacheco, and C. Pulgarin, "Structural properties and photoreactivity relationships of substituted phenols in $\mathrm{TiO}_{2}$ suspensions," Applied Catalysis B, vol. 43, no. 3, pp. 293-301, 2003.

[4] D. Chen and A. K. Ray, "Photodegradation kinetics of 4nitrophenol in $\mathrm{TiO}_{2}$ suspension," Water Research, vol. 32, no. 11, pp. 3223-3234, 1998.

[5] V. Augugliaro, M. J. López-Muños, L. Palmisano, and J. Soria, "Influence of $\mathrm{pH}$ on the degradation kinetics of nitrophenol isomers in a heterogeneous photocatalytic system," Applied Catalysis A, vol. 101, no. 1, pp. 7-13, 1993.

[6] V. Augugliaro, L. Palmisano, M. Schiavello, et al., "Photocatalytic degradation of nitrophenols in aqueous titanium dioxide dispersion," Applied Catalysis, vol. 69, no. 1, pp. 323-340, 1991.

[7] K. E. O'Shea and C. Cardona, "Hammett study on the $\mathrm{TiO}_{2}$ catalyzed photooxidation of para-substituted phenols. A kinetic and mechanistic analysis," Journal of Organic Chemistry, vol. 59, no. 17, pp. 5005-5009, 1994.
[8] S. Parra, J. Olivero, and C. Pulgarin, "Relationships between physicochemical properties and photoreactivity of four biorecalcitrant phenylurea herbicides in aqueous $\mathrm{TiO}_{2}$ suspension," Applied Catalysis B, vol. 36, no. 1, pp. 75-85, 2002.

[9] M. Salaices, B. Serrano, and H. I. de Lasa, "Photocatalytic conversion of phenolic compounds in slurry reactors," Chemical Engineering Science, vol. 59, no. 1, pp. 3-15, 2004.

[10] A. Assabane, Y. A. Ichou, H. Tahiri, C. Guillard, and J.-M. Herrmann, "Photocatalytic degradation of polycarboxylic benzoic acids in UV-irradiated aqueous suspensions of titania. Identification of intermediates and reaction pathway of the photomineralization of trimellitic acid (1,2,4-benzene tricarboxylic acid)," Applied Catalysis B, vol. 24, no. 2, pp. 71-87, 2000.

[11] E. Kusvuran, A. Samil, O. M. Atanur, and O. Erbatur, "Photocatalytic degradation kinetics of di- and tri-substituted phenolic compounds in aqueous solution by $\mathrm{TiO}_{2} / \mathrm{UV}$," Applied Catalysis B, vol. 58, no. 3-4, pp. 211-216, 2005.

[12] S. Parra, C. Pulgarín, S. Malato, J. Blanco, and P. Peringer, "Concentrating vs. nonconcentrating reactor for solar photocatalytic degradation of p-nitrotoluene sulfonic acid," in Proceeding of the 2nd International Conference on Oxidation Technologies for Water and Wastewater Treatment, Cutec Institut $\mathrm{GmbH}$, Clausthal-Zellerfeld, Germany, May 2000.

[13] E. Kusvuran and O. Erbatur, "Degradation of aldrin in adsorbed system using advanced oxidation processes: comparison of the treatment methods," Journal of Hazardous Materials, vol. 106, no. 2-3, pp. 115-125, 2004.

[14] F. J. Benítez, J. Beltrán-Heredia, J. L. Acero, and M. L. Pinilla, "Ozonation kinetics of phenolic acids present in industrial wastewaters from olive oil mills," Industrial and Engineering Chemistry Research, vol. 36, no. 3, pp. 638-644, 1997.

[15] I. Casero, D. Silicia, S. Rubio, and D. Perez Bendito, "Chemical degradation of aromatic amines by Fenton's reagent," Water Research, vol. 31, no. 8, pp. 1985-1995, 1997.

[16] O. Legrini, E. Oliveros, and A. M. Braun, "Photochemical processes for water treatment," Chemical Reviews, vol. 93, no. 2, pp. 671-698, 1993.

[17] K. Tanaka, W. Luesaiwong, and T. Hisanaga, "Photocatalytic degradation of mono-, di- and trinitrophenol in aqueous $\mathrm{TiO}_{2}$ suspension," Journal of Molecular Catalysis A, vol. 122, no. 1, pp. 67-74, 1997.

[18] R. W. Matthews, "Kinetics of photocatalytic oxidation of organic solutes over titanium dioxide," Journal of Catalysis, vol. 111, pp. 264-272, 1988.

[19] J.-M. Herrmann, "Heterogeneous photocatalysis: fundamentals and applications to the removal of various types of aqueous pollutants," Catalysis Today, vol. 53, no. 1, pp. 115-129, 1999.

[20] J.-M. Herrmann, "Photocatalysis," in Kirk-Othmer Encyclopedia of Chemical Technology, vol. 19, pp. 73-115, WileyInterscience, New York, NY, USA, 5th edition, 2006.

[21] A. Di Paola, V. Augugliaro, L. Palmisano, G. Pantaleo, and E. Savinov, "Heterogeneous photocatalytic degradation of nitrophenols," Journal of Photochemistry and Photobiology A, vol. 155, no. 1-3, pp. 207-214, 2003.

[22] D. Curcó, S. Malato, J. Blanco, J. Giménez, and P. Marco, "Photocatalytic degradation of phenol: comparison between pilotplant-scale and laboratory results," Solar Energy, vol. 56, no. 5, pp. 387-400, 1996.

[23] C. Minero, E. Pelizzetti, S. Malato, and J. Blanco, "Large solar plant photocatalytic water decontamination: effect of operational parameters," Solar Energy, vol. 56, no. 5, pp. 421-428, 1996. 
[24] R. Goslich, D. Ralf, and D. Bahnnemann, "Solar water treatment: principles and reactors," Water Science and Technology, vol. 35, no. 4, pp. 137-148, 1997.

[25] J.-M. Herrmann, J. Disdier, P. Pichat, S. Malato, and J. Blanco, " $\mathrm{TiO}_{2}$-based solar photocatalytic detoxification of water containing organic pollutants. Case studies of 2,4dichlorophenoxyaceticacid (2,4-D) and of benzofuran," Applied Catalysis B, vol. 17, no. 1-2, pp. 15-23, 1998. 


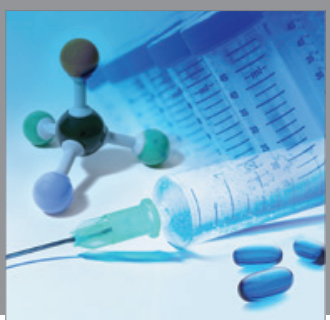

International Journal of

Medicinal Chemistry

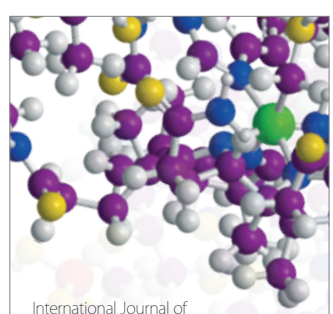

Carbohydrate Chemistry

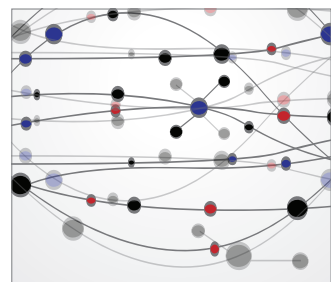

The Scientific World Journal
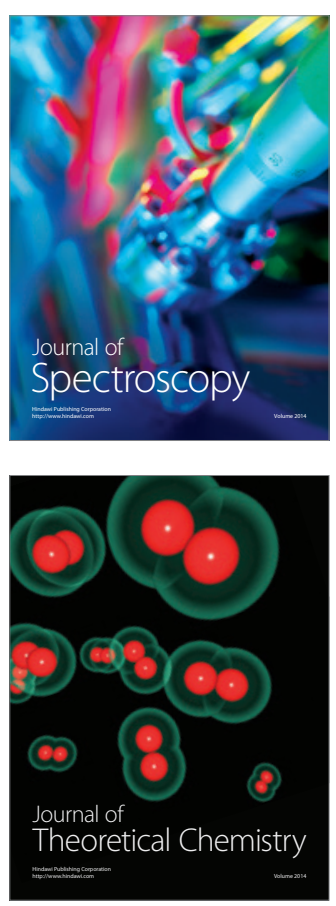
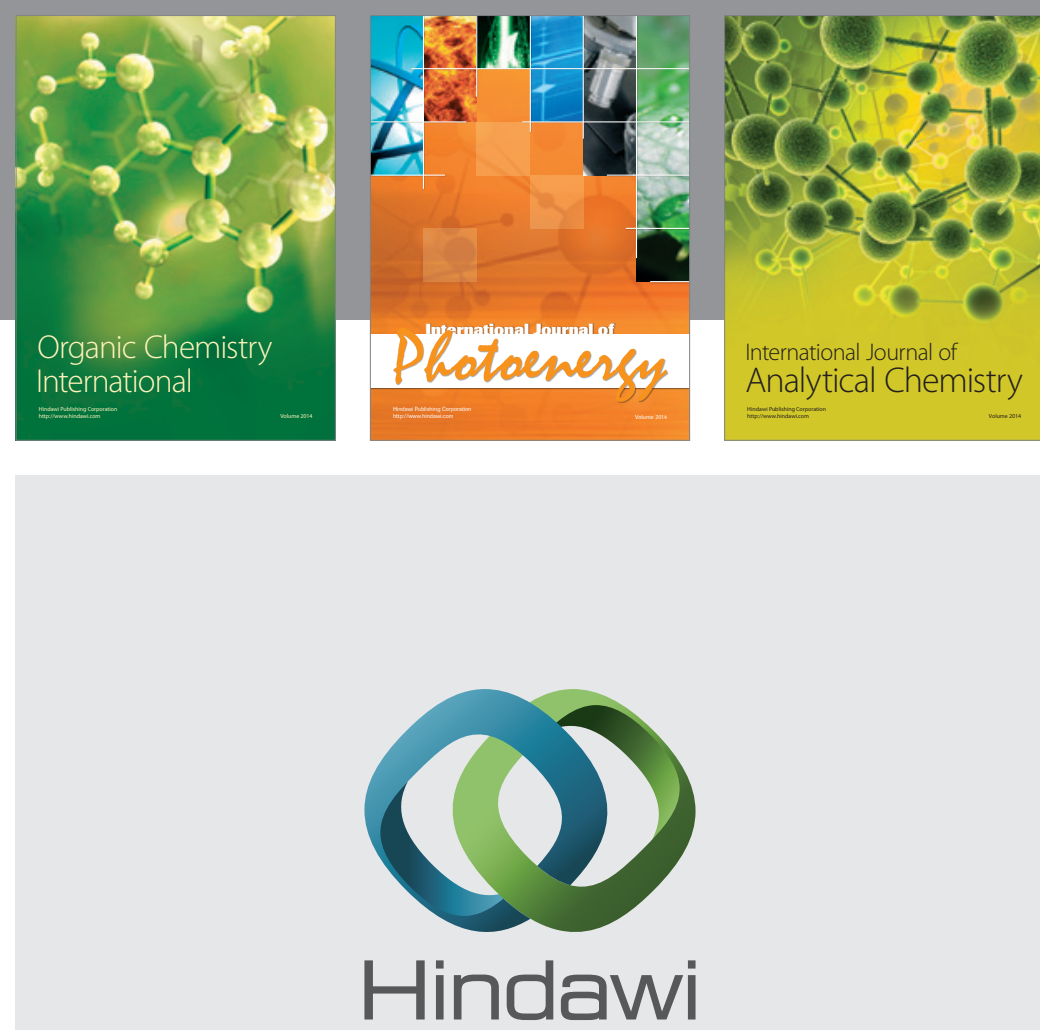

Submit your manuscripts at

http://www.hindawi.com
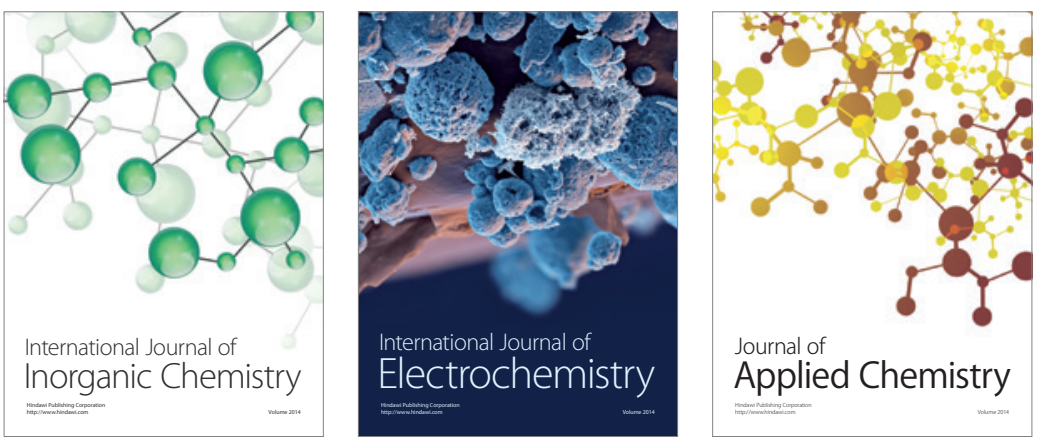

Journal of

Applied Chemistry
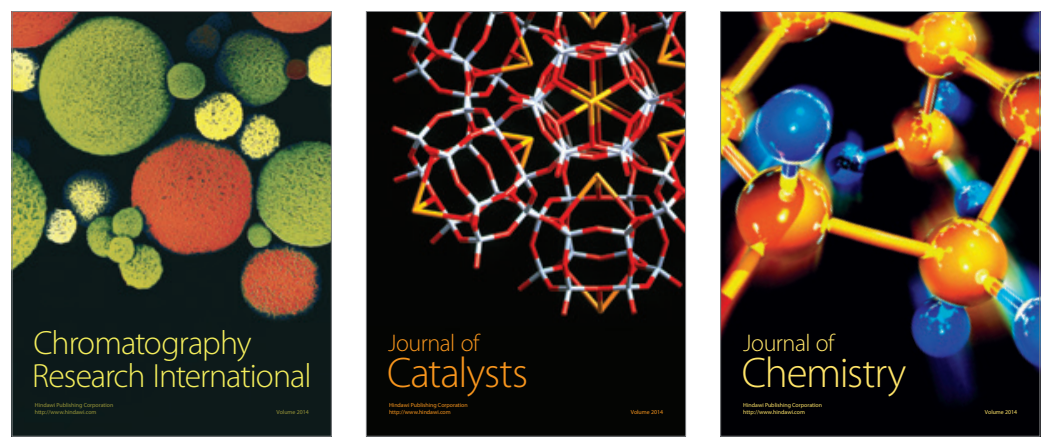
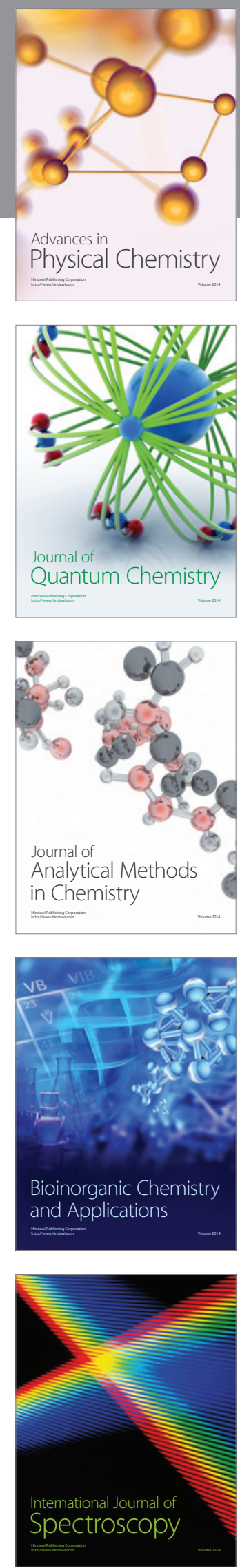